\title{
PEMBERDAYAAN AKSEPTOR DAN KADER MENGENAL EFEK SAMPING KONTRASEPSI HORMONAL DI PUSTU TANJUNG KABUPATEN ENDE
}

DOI: https://doi.org/10.33024/jkpm.v4i4.3804

\author{
Martina Bedho ${ }^{1 *}$, Khrispina Owa ${ }^{2}$, Yoseph Woge ${ }^{3}$, Fitria Syafrudin Pua Sawa ${ }^{4}$ \\ ${ }^{1-4}$ Program Studi Keperawatan Ende, Poltekkes Kemenkes Kupang \\ Jln.Prof.Dr.W.Z Yohanes Ende. \\ Kode Pos: 6318 Ende, NTT Indonesia
}

Disubmit: 4 Februari 2021 Diterima: 17 Februari 2021 Diterbitkan: 01 Agustus 2021

Email Korespondensi: marthina.bedho@gmail.com

\begin{abstract}
ABSTRAK
Peserta KB aktif dan akseptor KB baru di kabupaten Ende 53,2 \%, lebih memilih menggunakan alat kontrasepsi hormonal sedangkan pemilihan alat kontrasepsi lain berada dibawah 20\%. Alat kontrasepsi suntik yang paling banyak digunakan, berikutnya implant dan pil. Akseptor yang mengalami efek samping kenaikan berat badan dan hipertensi 32 orang $(11,03 \%)$, dan akseptor terbanyak berada di Puskesmas pembantu Tanjung. Tujuan pengabdian masyarakat ini adalah pemberdayaan akseptor dan kader kesehatan mengenal efek samping penggunaan kontrasepsi hormonal, dimana sasarannya adalah kader dan akseptor. Metode yang digunakan adalah screening,ceramah, diskusi, simulasi dan praktikum oleh khalayak sasaran. Hasil pengabdian masyarakat menunjukan semua akseptor memiliki pengetahuan baik $(83,33 \%)$ pada pretest sedangkan posttest $(100 \%)$ namun belum tahu tentang lama penggunaan kontrasepsi hormonal baik secara suntik, implant dan pil. Keterampilan yang dicapai adalah semua kader dan akseptor 28 orang (100\%) dapat mengukur tinggi badan, menimbang berat badan, dan mengukur tekanan darah. Diharapkan pengamatan yang intensif dari bidan Pustu Tanjung dan dapat diperdaya oleh kader KB untuk membantu mengawasi efek samping kontrasepsi hormonal.
\end{abstract}

Kunci : Pemberdayaan akseptor dan kader, efek samping kontrasepsi hormonal.

\begin{abstract}
$53.2 \%$ of active family planning participants and new family planning acceptors in Ende district prefer to use hormonal contraceptives while the choice of other contraceptives is below 20\%. The most widely used injectable contraceptives are implants and pills. There were 32 acceptors who experienced side effects of weight gain and hypertension (11.03\%), and the most acceptors were in the Tanjung auxiliary health center. Research in Kumasi sub-district, Ghana, India, because some acceptors experienced long and heavy menstruation, spoting, no menstruation, and vaginal discharge so they were afraid of modern contraceptive methods (Kimberly Daniels, 2015). The aim of this community service is to empower
\end{abstract}


acceptors and health cadres to recognize the side effects of using hormonal contraceptives, where the targets are cadres and acceptors. The methods used are screening, lectures, discussions, simulations and practicum by the target audience. The results of community service show that all acceptors have good knowledge (83.33\%) at pretest while posttest (100\%), but they do not know about the length of time using hormonal contraceptives both by injection, implant and pill. The skill achieved is that all 28 cadres and acceptors (100\%) can measure height, weigh body weight, and measure blood pressure. It is hoped that intensive observation from the midwife of Pustu Tanjung and the family planning cadres can help to monitor the side effects of hormonal contraception.

Keywords : Empowerment of acceptors and cadres, side effects of hormonal contraception.

\section{PENDAHULUAN}

Pencapaian program Indonesia sehat demi meningkatkan derajat kesehatan masyarakat dengan focus utama keluarga mengikuti program keluarga berencana dihadapkan pada suatu permasalahan dimana penggunaan kontrasepsi baik kontrasepsi hormonal ataupun alat kontrasepsi dalam rahim (AKDR) selalu ada efek samping. Efek samping menjadi penyebab utama tidak terpenuhnya angka kebutuhan berkB saat ini $(9,5 \%)$. Setiap efeksamping direspon tubuh berbeda-beda pada masing - masing akseptor.

Beberapa penelitian, ditemukan di Indonesia oleh(Rahayu, 2017),(Sukardi Saleh, 2019), dan (Karimang, 2020), efek samping KB suntik dan pil berupa gangguan haid, depresi, rambut rontok, jerawat, perubahan libido, tidak haid, keputihan, mual muntah, pusing, perubahan berat badan, peningkatan teknan darah, kloasma, psikis depresi ringan dan psikis depresi berat. Sedangkan pada penggunaan IUD efek samping yang dialami berupa, pendarahan spoting antar haid, haid lebih lama dan banyak bahkan ada yang sampai anemia. Sebagian akseptor mengalami keputihan, ekspulsi dan dispareuni.Sejalan dengan penelitian (Setyoningsih, 2020) bahwa dari 51 responden yang mengalami efek samping gangguan haid berupa amenorea yaitu sebesar 31 responden (60,8\%), gangguan haid berupa spotting yaitu sebesar 17 responden $(33,3 \%)$, mengalami keputihan yaitu sebesar 18 responden (35,3\%), mengalami kenaikan berat badan yaitu sebesar 29 responden (56,9\%), mengalami pusing/sakit kepala yaitu sebesar 18 responden (35,3\%), mual/muntah yaitu sebesar 16 responden (31,4\%). Hasil yang sama dari penelitian (Bedho, 2019) menunjukan ada pengaruh lama penggunaan kontrasepsi hormonal terhadap kejadian obesitas $p=0,035$ ( $p=\leq$ 0,005). Uji regresi logistic menunjukan ratio kejadian sekurang-kurangnya beresiko 1,129 kali, paling besar lebih berisiko 9,605 menderita obesitas. Ada pengaruh penggunaan kontrasepsi hormonal terhadap kejadian obesitas $p$-value $=0,035(\mathrm{p}=\leq 0,005)$, dengan ratio sekurang-kurangnya beresiko 1,672, paling besar lebih berisiko 3,020 menderita obesitas. Sementara hasil penelitian (lqmy, 2021), tahun 2021 ditemukan ada hubungan riwayat pemakaian kontrasepsi hormonal dengan kanker payudara OR $=5.000$. Penelitian di kecamatan Kumasi Ghana, India karena sebagian akseptor mengalami haid yang lama dan banyak, 
spoting, tidak haid, dan keputihan sehingga mereka takut akan metode kontrasepsi modern (Daniels, 1982 - 2010). Hasil ini menginformasikan kepada petugas kesehatan lebih khusus kepada bidan untuk lebih intensif memberikan pendidikan kesehatan ataupun konseling kepada akseptor agar menurunkan angka kejadian efek samping kontrasepsi keluarga berencana.Tujuan pengabdian masyarakat ini memperdayakan kader dan akseptor dalam mengenal tanda tanda adanya efek samping penggunaan kontrasepsi hormonal.

\section{MASALAH}

Penelitian Bedho (2019) berlokasi di 3 Puskesmas yakni Rukun Lima, Onekore dan Rewarangga. Responden yang paling banyak menggunakan kontrasepsi hormonal dan mengalami obesitas yakni dari kampung KB Pustu Tanjung Puskesmas Rukun Lima. Hal ini memotivasi tim untuk memberikan pengabdian masyarakat berjudul “ Pemberdayaan Akseptor Dan Kader Mengenal Efek Samping Kontrasepsi Hormonal di Pustu Tanjung, Kabupaten Ende”.

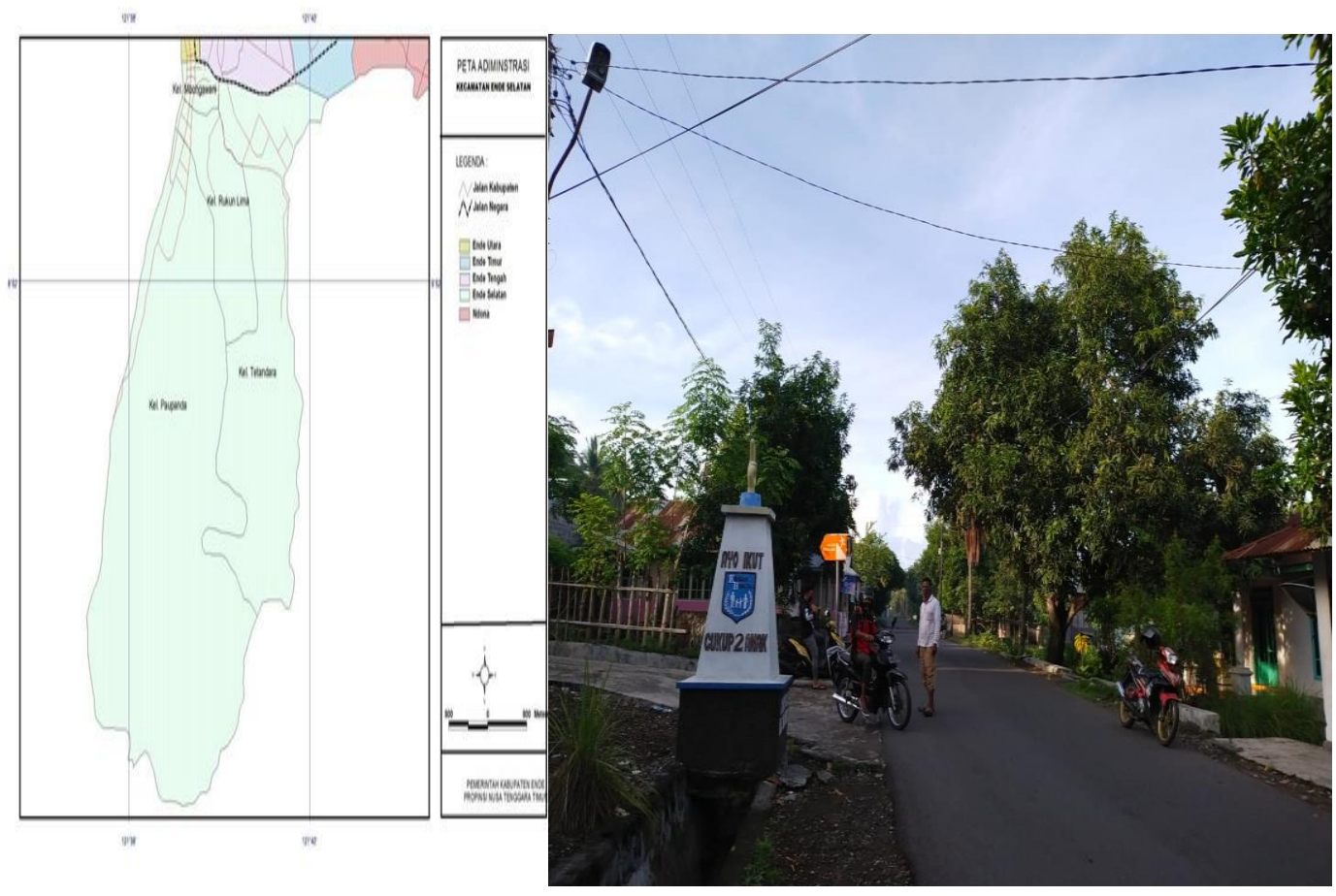

Gambar 2.1 Peta wilayah dan lokasi pengabdian masyarakat 


\section{METODE}

Metode yang digunakan dalam pengabdian masyarakat ini :

1. Diawalipre test tentang efek samping penggunaan kontrasepsi hormonal.

2. Ceramah untuk pemberian makalah tentang mengenal efek samping penggunaan kontrasepsi hormonal.

3. Diskusi dan tanyajawab digunakan dalam post tes.

4. Praktikum oleh sasaran, dimana akseptor dan kader diberikan pelatihan mengukut berat badan, tinggi badan dan tekanan darah.Jumlah peserta28 orang terdiri dari 16 kader KB dan 12 orang akseptor KB hormonal.

5. Alat dan bahan yang digunakan adalah : Timbangan, skala tinggi badan, tensi meter, leaflet dan buku saku berjudul mengenal efek samping penggunaan kontrasepsi hormonl.

\section{HASIL DAN PEMBAHASAN}

\section{1 HASIL}

Pengabdian masyarakat ini dilaksanakan pada hari Jumat tanggal 6 Nopember 2021 bertempat di aula Kelurahan Tanjung dari jam 08.00 - 12.00 WITA, dengan hasil sebagai berikut:

\subsubsection{Pengetahuan}

Kegiatan pengabdian masyarakat ini perlu diukur pengetahuan akseptor tentang penggunaan kontrasepsi hormonal dimana terdapat hasil penelitian (Utami, 2015) ditemukan pengetahuan akseptor kurang baik $(51, \%)$ dan ada hubungan pengetahuan akseptor KB terhadap penggunaan kontrasepsi $p$-Value $=0,034$ $\mathrm{OR}=0,16$. Untuk mengetahui pengetahuan akseptor maka didahului dengan pre test, lalu memberikan materi tentang efek saamping kontrasepsi hormonal. Selanjutnya dilakukan post test menggunakan 6 pertanyaan yang sama dengan pre test dan disusun oleh tim pengabdian masyarakat. Hasilnya dilaporkan bahwa 28 peserta berpengetahuan baik (100\%) dimana masing- masing mendapatkan nilai 83,33 , hanya ada satu pertanyaan yang tidak dapat dijawab adalah berapa lama penggunaan kontrasepsi baik pil, suntik maupun implant. Sementara post test dilakukan setelah pemberian materi dengan hasil semua peserta 28 orang (100\%) berpengetahuan baik.

4.1.2 Keterampilan

Pada pengabdian masyarakat ini dilakukan pelatihan pengukuran berat badan, tinggi badan dan tekanan darah. Semua peserta dibimbing oleh tim pengabdian masyarakat dan bidan dari Pustu Tanjung. Selanjutnya diberi kesempatan peserta melakukan simulasi 2 kali baru dilakukan evaluasi dari masing- masing peserta. Hasilnya, 28 peserta (100\%) dapat mengukur berat badan, tinggi badan dantekanan darah. Tekanan darah memang butuh latihan lagi untuk lebih terbiasa mendengar, agar lebih tepat menentukan bunyi systole dan diastole. 


\subsection{PEMBAHASAN}

\subsubsection{Pengetahuan}

Pengetahauan peserta pada hasil pre test baik dari 28 peserta (100\%) dengan nilai 8333 namun dari 6 pertanyaan yang diajukan, akseptor dan kader KB tidak dapat menjawab tentang lama penggunaan kontrasepsi hormonal baik secara suntik, implant maupun pil. Hal ini dapat mempengaruhi efek samping penggunaan kontrasepsi hormonal oleh akseptor, jika digunakan terlalu lama. Sesuai hasil penelitian (Bedho, 2019) menunjukan ada pengaruh lama penggunaan kontrasepsi hormonal terhadap kejadian obesitas $p=0,035$ ( $p=\leq$ 0,005). Uji regresi logistic menunjukan ratio kejadian sekurang-kurangnya beresiko 1,129 kali, paling besar lebih berisiko 9,605 menderita obesitas.

Pada sesi berikut pemberian materi tentang Mengenal efek samping penggunaan kontrasepsi hormonal yang dirasakan akseptor. Selanjutnya dilakukan evaluasi (post test) tanya jawab dengan hasil pengetahuan post test dari akseptor dan kader KB yang hadir baik (100\%). Pengetahuan merupakan hasil dari tahu setelah terjadi interaksi oleh indra manusia, interaksi ini terjadi melalui informasi baik secara langsung melalui pendidikan kesehatan maupun melalui media. Sesuai pernyataan (Egi Ade, 2015) bahwa pendidikan kesehatan yang efektif meningkatkan pengetahuan seseorang yang sejalan dengan penelitian (Anggraini, 2018) dimana uji statistik t-tes didapat nilai p-value 0.000 $(<0.05)$ yang artinya terdapat pengaruh pemberian pendidikan kesehatan dengan sikap ibu dalam menggunakan alat kontrasepsi

Walaupun pada post test ini akseptor dan kader telah mendapatkan predikat baik pada pengetahuan tentang mengenal efek samping kontrasepsi hormonal, hal ini karena akseptor dan kader mendapatan pendidikan kesehatan. Untuk itu sangat dianjurkan kepada bidan untuk terus menerus memberikan konseling ataupun pendidikan kesehatan dan tegas mengatakan kepada akseptor untuk mengganti alat kontrasepsi hormonal jika sudah tiba saatnya berhenti atau aff.

\subsubsection{Keterampilan.}

Keterampilan yaitu kemampuan untuk menggunakan akal, fikiran, ide dan kreatifitas dalam mengerjakan, mengubah ataupun membuat sesuatu menjadi lebih bermakna sehingga menghasilkan sebuah nilai dari hasil pekerjaan tersebut (KBBI, 2015). Keterampilan ini dibutuhkan kader KB dalam mengidentifikasi efek samping penggunaan kontrasepsi hormonal menggunakan pengukuran berat badan dan tekanan darah. Berdasarkan hasil penelitian Bedho (2019) ditemukan hasil pengawasan bidan dalam pelayanan kontrasepsi 8 orang $(34,78 \%)$ dan yang tidak ada pengawasan bidan 15 orang ( $65,22 \%)$ uji statistic Chi-Square $p$-value $=(p=>0,005), p$-value $=0,108$ pada obesitas. Hal ini menunjukan tidak ada pengaruh pengawasan bidan dalam pelayanan kontrasepsi hormonal terhadap kejadian hipertensi dan obesitas. Walaupun secara statistik pengawasan bidan tidak menunjukan pengaruh terhadap kejadian hipertensi dan obesitas tetapi sebuah kelalaian atau belum terampil dalam pengawasan pelayanan dalam mengikuti riwayat kesehatan 
akseptor setiap kunjungan ulang sejak digunakanya kontrasepsi hormonal dapat menjadi risiko terjadinya efek samping seperti hipertensi dan obesitas.

Kader KB dipilih diharapkan sebagai perpanjangan tangan bidan dalam menyampaikan informasi kesehatan tentang efek samping penggunaan kontrasepsi hormonal. Kader yang senantiasa bersama masyarakat dapat menyampaikan informasi kesehatan secara non formal dalam aktifitas hariannya. Informasi ini sangat perlu diperhatikan oleh petugas kesehatan dalam hal ini bidan harus tetap dan selalu mengawasi setiap akseptor yang datang untuk melakukan pengukuran ulang tekanan darah dan timbang berat badan pada waktu kunjungan ulang. Setiap akseptor harus dideteksi riwayat kesehatannya sejak awal pemakaian kontrasepsi agar gejala yang mengarah ke efek samping segera ditangani. Kader dapat membantu mengamati akseptor pengguna kontrasepsi hormonal jika mengetahui apa yang seharusnya diobservasi seperti mengukur berat badan, dan tekanan darah.

Kegiatan pengabdian masyarakat ini diberikan pelatihan, menimbang berat badan, dan mengukur tinggi badan kepada kader dan akseptor agar dapat membantu menyebar luaskan efek samping obesitas dalam penggunaan kontrasepsi hormonal. Sedangkan latihan mengukur tekanan darah untuk menyiapkan kader mengidentifikasi efek samping hipertensi. Pada simulasi pelatihan pengukuran tinggi badan, berat badan dan tekanan darah langsung dengan bimbingan tim pengabdian masyarakat dan bidan Puskesmas Pembantu Tanjung.

Evaluasi keterampilan dilakukan pada saat kegiatan berlangsung, yang mana kader dan akseptor diberikan kesempatan mensimulasi pengukuran berat badan, tinggi badan, dan tekanan darah yang diamati dan diuji oleh bidan dan tim pengabdian masyarakat. Hasil dari pelatihan adalah semua kader, dan akseptor ( $100 \%$ ) dapat melakukan pengukuran tinggi badan, tekanan darah dan berat badan.

Sebagai pegangan bagi Bidan dan 16 kader dalam melakukan pengamatan efek samping penggunaan kontrasepsi hormonal, diberikan buku pegangan berjudul: Mengenal Efek Samping Penggunaan Kontrasepsi Hormonal.

Tahap selanjutnya pada kegiatan monitoring dan evaluasi keterampilan para kader dalam melakukan pengukuran tinggi badan, tekanan darah berat badan dan tekanan darah, dilaporkan bidan Puskesmas Pembantu Tanjung bahwa sebelum dilakukan ke akseptor masih dibimbing ulang oleh bidan, sehingga lebih paham dan akhirnya kader sudah dapat melakukan pengukuran dengan baik.

Diharapkan kader terampil dalam pengukuran, tinggi badan, tekanan darah dan berat badan, sehingga dapat didayagunakan untuk membantu bidan dalam pengamatan penggunaan kontrasepsi hormonal, agar obesitas dan hipertensi dapat dicegah pada akseptor pengguna kontrasepsi hormonal 
3. Foto kegiatan
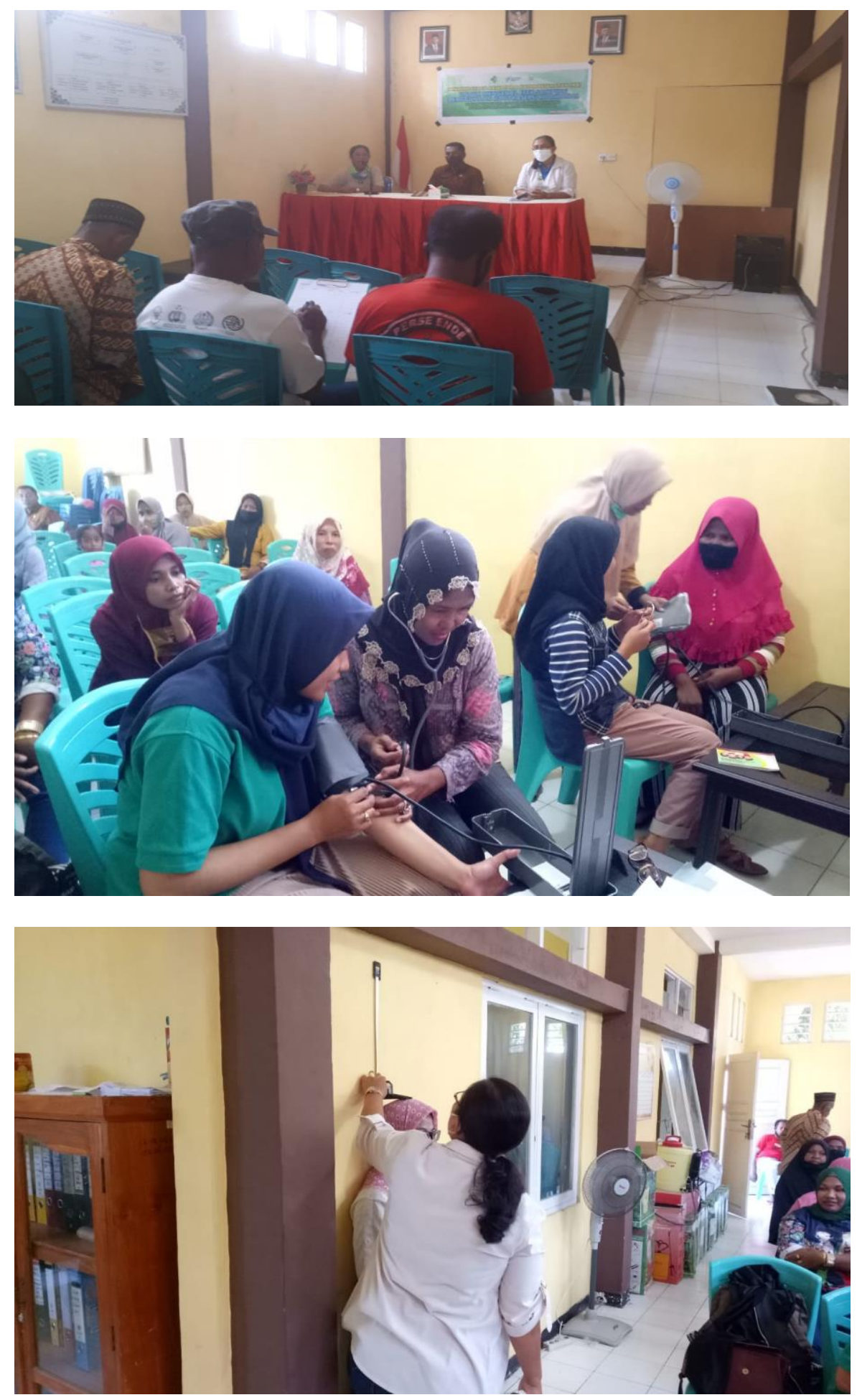

Gambar 4. Kegiatan Pengabdian Kepada Masyarakat 


\section{KESIMPULAN}

Efek samping penggunaan kontrasepsi hormonal paling banyak di kampung KB adalah obesitas dan sedikit hipertensi. Dengan pelatihan pada pengadian masyarakat ini Kader KB dapat didayagunakan untuk membantu bidan dalam pengamatan penggunaan kontrasepsi hormonal,sehingga dapat mengenal tanda-tanda obesitas dan hipertensi.

\section{DAFTAR PUSTAKA}

Anggraini. (2018). Pengaruh penyuluhan Pendidikan Kesehatan Terhadap Sikap Dalam Memilih Kontrasepsi. Jurnal Kebidanan Malahayati , Vol.4. No.4.

Bedho. (2019). Pengaruh Penggunaan Kontrasepsi Hormonal Terhadap Kejadian Obesitas Di Puskesmas Wilayah Kota Ende. Ende.

Bernadetha. (2017). Klinik Hukum On Line. Surakarta.

Daniels, K. (1982 - 2010). Contraception Methods Women Have Used: United State . MBC Public Health , pp. 15-118.

Egi Ade, d. (2015). Pendidikan Kesehatan Dengan Media SlideEfektif meningkatkan Pengetahuan Perawatan. Artikel , ISSN: 1978-0579-ISSN 2354-7642.

lqmy, d. (2021). Faktor Risiko Yang Berhubungan Dengan Kanker Payudara. Jurnal Kebidanan Malahayati, Vol 7, No 1.

Karimang, d. (2020). Faktor Yang Berhubungan Dengan Penggunaan Kontrasepsi Suntik 3 Bulan Diwilayah Puskesmas Tagulandangkabupaten Sitaro. Jurnal Keperawatan , 10-22.

KBBI. (2015). Kamus Besar Bahasa Indonesia. Jakarta.

Rahayu, D. (2017). Efek Samping Akseptor Kb Suntik Depo Medroksi Progesterone Acetat (Dmpa)Setelah 2 Tahun Pemakaian. jurnal Kesehatan Samodra Ilmu.

Setyoningsih. (2020). Efek Samping Akseptor KB Suntik Depo Medrosik Progesteron Asetat (DMPA) Di BPM Fitri Hayati. Jurnal Kebidanan Malahayati.

Sukardi Saleh, d. (2019). Analisis Faktor Yang Berhubungan Dengan Kejadian Efek Samping. Pada Akseptor Putus Pakai IUD/Implan Di Kabupaten Mamuju Tengah. Jurnal Kebidanan, 43 - 50.

Utami. (2015). Hubungan Pengetahuan Dan Pendidikan Akseptor KBTerhadap Penggunaan Alat Kontrasepsi Di BPS Sulsasmi S.STKecamatan Raja Basa Bandar Lampung. Jurnal Kesehatan Holistik Malahayati , Vol.9, No1. 33-36. 